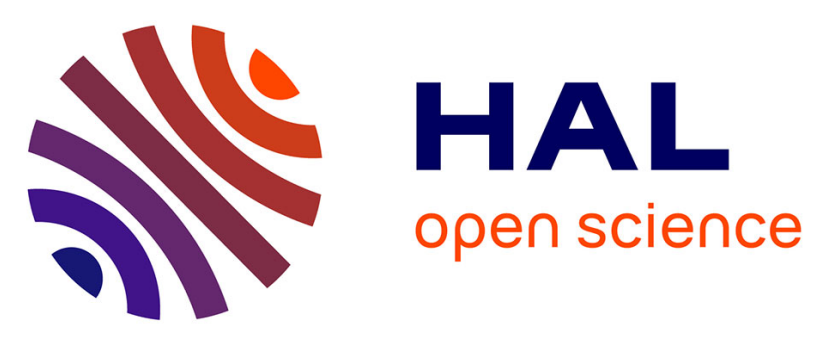

\title{
Functional bioactive glass topcoats on hydroxyapatite coatings: Analysis of microstructure and in-vitro bioactivity
}

Andrea Cattini, D. Bellucci, Antonella Sola, Lech Pawlowski, Valeria Cannillo

\section{- To cite this version:}

Andrea Cattini, D. Bellucci, Antonella Sola, Lech Pawlowski, Valeria Cannillo. Functional bioactive glass topcoats on hydroxyapatite coatings: Analysis of microstructure and in-vitro bioactivity. Surface and Coatings Technology, 2014, 240, pp.110-117. 10.1016/j.surfcoat.2013.12.023 . hal-01102628

\section{HAL Id: hal-01102628 \\ https://hal-unilim.archives-ouvertes.fr/hal-01102628}

Submitted on 13 Jan 2015

HAL is a multi-disciplinary open access archive for the deposit and dissemination of scientific research documents, whether they are published or not. The documents may come from teaching and research institutions in France or abroad, or from public or private research centers.
L'archive ouverte pluridisciplinaire HAL, est destinée au dépôt et à la diffusion de documents scientifiques de niveau recherche, publiés ou non, émanant des établissements d'enseignement et de recherche français ou étrangers, des laboratoires publics ou privés. 


\title{
Functional bioactive glass topcoats on hydroxyapatite coatings: Analysis of microstructure and in-vitro bioactivity
}

\author{
Andrea Cattini ${ }^{\mathrm{a}, \mathrm{b}, *}$, Devis Bellucci ${ }^{\mathrm{a}}$, Antonella Sola ${ }^{\mathrm{a}}$, Lech Pawłowski ${ }^{\mathrm{b}}$, Valeria Cannillo ${ }^{\mathrm{a}}$ \\ a Department of Engineering “Enzo Ferrari”, University of Modena and Reggio Emilia, Via Vignolese, 905-41125 Modena (MO), Italy \\ b SPCTS, UMR CNRS 7315, University of Limoges, F-87068 Limoges, France
}

\section{A R T I C L E I N F O}

Article history:

Received 5 September 2013

Accepted in revised form 13 December 2013

Available online 19 December 2013

\section{Keywords:}

Suspension plasma spraying

Bioactive glass

Functional coating

\begin{abstract}
A B S T R A C T
A bioactive glass topcoat was introduced to modify the surface morphology and in-vitro reactivity of hydroxyapatite (HA) coatings for biomedical applications. With this aim, a CaO-rich bioactive glass, termed BG_Ca (wt.\%: 4.7 $\mathrm{Na}_{2} \mathrm{O}, 42.3 \mathrm{CaO}, 6.1 \mathrm{P}_{2} \mathrm{O}_{5}$, and $46.9 \mathrm{SiO}_{2}$ ), was selected due to its good bioactivity and low tendency to crystallize at high temperature. The standard HA coatings were sprayed through atmospheric plasma spray (APS) on steel substrates starting from commercial powders ("APS-HA" samples). The HA coatings, in turn, were subsequently coated with a thin layer of bioactive glass by suspension plasma spray (SPS), thus obtaining the duplex systems ("APS-HA/SPS-BG_Ca" samples). The samples with and without the BG_Ca layer were analysed by microstructural characterization and by in vitro tests in simulated body fluid (SBF). The analysis revealed an increased reactivity of the APS-HA/SPS-BG_Ca samples compared to the glass-free APS-HA coatings.
\end{abstract}

(C) 2013 Elsevier B.V. All rights reserved.

\section{Introduction}

Over the last decades, biomedical sciences have acquired a growing importance. In particular, the progressive ageing of population and diffusion of morbid obesity, with related musculoskeletal disorders, are driving the development of innovative materials for bone implants [1]. Though the production of biomedical devices is nowadays a mature and well-established practice, the research is constantly evolving with the aim of improving the reliability and effectiveness of the available prostheses, thus increasing their life expectancy in service conditions [2].

Hydroxyapatite, $\mathrm{HA}\left(\mathrm{Ca}_{10}\left(\mathrm{PO}_{4}\right)_{6}(\mathrm{OH})_{2}\right)$, is a calcium phosphate ceramic whose composition and structure are very similar to those of the mineral component of bone. It is therefore osteoconductive, with an excellent biocompatibility which allows bone cells to grow on its surface [3]. For this reason, HA is currently applied in orthopaedics and dentistry with very encouraging results [4]. Unfortunately HA is brittle and hence it is not suitable for structural applications. A way to overcome this problem is to use HA as a coating on a metal implant, which would provide the required mechanical strength. Nowadays, the plasma spraying is the standard method to produce HA coatings $[5,6]$. In fact, this method makes it possible to achieve a high deposition rate, which results in high coating production rate; moreover plasma sprayed HA coatings, in turn, may reach a suitable adhesion to the substrate [7]. Although the plasma spray process has been thoroughly studied and optimized in recent years, some isolated cases of implant failure are still reported and revision surgeries are sometimes necessary [8].

\footnotetext{
* Corresponding author at: Department of Engineering “Enzo Ferrari”, University of
} Modena and Reggio Emilia, Via Vignolese, 905-41125 Modena (MO), Italy.
Moreover the host tissue-HA bonding reactions begin after several hours after implantation, and therefore HA coatings are not the optimum solution if a fast fixation is required $[4,9]$. Consequently, numerous studies address the development of new bioactive coatings [10-12]. Similarly, much research has been performed on both alternative materials and innovative deposition techniques [13-16]. An example of an emerging family of biomedical materials is given by bioactive glasses. They are particularly interesting, because they possess the highest degree of bioactivity controlled by their chemical composition [17]. In particular, 45S5Bioglass ${ }^{\circledR}$ (in wt.\%: $24.5 \mathrm{Na}_{2} \mathrm{O}, 24.5 \mathrm{CaO}, 6 \mathrm{P}_{2} \mathrm{O}_{5}, 45$ $\mathrm{SiO}_{2}$ ) is the most representative glass of the so-called "Bioglass" family, first proposed by Prof. Hench at the end of the 1960s [18]. Due to their particular composition, bioglasses possess a strong bone-bonding ability; specific formulations are even able to connect to soft tissues [19]. Unfortunately, conventional bioglasses are likely to devitrify at high temperature and the development of crystalline phases is known to retard the original bioactivity [20]. Some new experimental compositions are about to emerge aiming at limiting the tendency to crystallize i.e. preserving the amorphous structure of the glass during hightemperature processes, such as sintering and thermal spray coating deposition [21,22]. A new strategy to obtain improved bioactive coatings may lead to the improvement of the deposition process. Indeed, even if plasma spraying is the most widely used technique to produce biomedical coatings, many innovations have been recently proposed, such as suspension plasma spraying (SPS) [23]. In this process, the feedstock is a liquid suspension of fine, nanometric or micrometric solids instead of the usual dry powder having micrometric size. This is a key point, since the dispersion of a solid powder in a liquid medium (water or organic solvent) makes it possible to process very fine particles or hygroscopic materials (such as bioactive glasses), which 
otherwise could not be employed in conventional thermal spraying because of their poor flowability. As a result of spraying process, a controlled microstructure, with very small (near-nanometric) intralamellar crystalline grains, can be obtained [24].

In the present study, a bioactive glass topcoat was applied by the innovative SPS technique on a conventional HA plasma sprayed coating. The BG_Ca glass (having composition, in wt.\%: $4.7 \mathrm{Na}_{2} \mathrm{O}, 42.3 \mathrm{CaO}, 6.1$ $\mathrm{P}_{2} \mathrm{O}_{5}$, and $46.9 \mathrm{SiO}_{2}$ ) was selected since it combines high bioactivity with a relatively low tendency to crystallize at high temperature $[25,26]$.

The aim of such functional duplex system was to merge the HA's biocompatibility and long term stability, which are useful to protect the metal substrate from the physiological environment, with the high bioactivity of the SPS bioactive glass top-coat.

In order to assess the effectiveness of the bioactive glass topcoat to accelerate the mineralization process in a physiological environment, the samples with and without a BG_Ca layer were tested in vitro, by soaking them in a simulated body fluid (SBF) [27].

\section{Materials and methods}

\subsection{Feedstock materials}

The hydroxyapatite (HA) powder was a commercial product manufactured by Tomita (Japan). The powder had a mean diameter of $d_{50}=120 \mu \mathrm{m}$, but it consisted of spray dried sub-micrometric particles having internal porosity of about $12 \%$ [28].

As described in a previous contribution [28], the bioactive glass (BG_Ca) $[25,26]$ was produced by the conventional melt-quenching method. Appropriate raw materials were mixed and then molten in a platinum crucible at $1450{ }^{\circ} \mathrm{C}$. The molten glass was poured into water. The obtained frit was dried overnight at $110{ }^{\circ} \mathrm{C}$ and dry milled in an agate mortar and sieved at $63 \mu \mathrm{m}$. The powder was further milled in an attrition system by using $0.8 \mathrm{~mm}$ zirconia balls and adding the dispersant Beycostat C213 (2 wt.\% of the dry powder). Since bioactive glass powders are water-reactive [29], ethanol was selected as the suspension liquid. The obtained BG_Ca powder had a monomodal distribution with a mean diameter of $d_{50}=4.7 \mu \mathrm{m}$ (determined with a granulometer Partica LA-950V2, Horiba). The feedstock suspension was formulated by dispersing $20 \mathrm{wt} . \%$ of solid phase in $80 \mathrm{wt} . \%$ of ethanol.

\subsection{Coatings' deposition}

Plasmaspray runs were performed using a SG-100 torch (Praxair, S.T., Indianapolis, IN, USA). Substrates were 316L stainless steel disks (diameter: $25 \mathrm{~mm}$; thickness: $8 \mathrm{~mm}$ ), preliminary sandblasted to a roughness $R_{\mathrm{a}}=4.3 \mu \mathrm{m}$ (determined by means of Tester T500, Hommel) and ultrasonically cleaned with ethanol and acetone. 316L steel was chosen because it has proved to be acceptable for orthopaedic implants over decades of use and currently it is widely diffused for fracture repair devices [30].

During the APS deposition, the HA powder was supplied by a laboratory powder feeder including an Ar-pressurized chamber and a vibrating system.

To deposit the BG_Ca topcoat, a pneumatic system was used to feed the suspension (Fig. 1a); to avoid agglomeration and sedimentation, the suspension was continuously agitated by a magnetic stirrer. Both feedstock materials were (separately) supplied into the plasma by internal injection. The injection orifice was radial inside the anode and mounted at $16 \mathrm{~mm}$ from torch's exit. A schematic representation of the SPS deposition process is shown in Fig. 1b.

Several deposition attempts were carried out using tentative parameters taken from the literature $[28,31]$. Then, based on the preliminary trials, the final spray parameters were defined, with the aim of optimizing the density and the thickness of the APS-HA layer and, at the same time, promoting the bioactivity of the glass topcoat, which should a

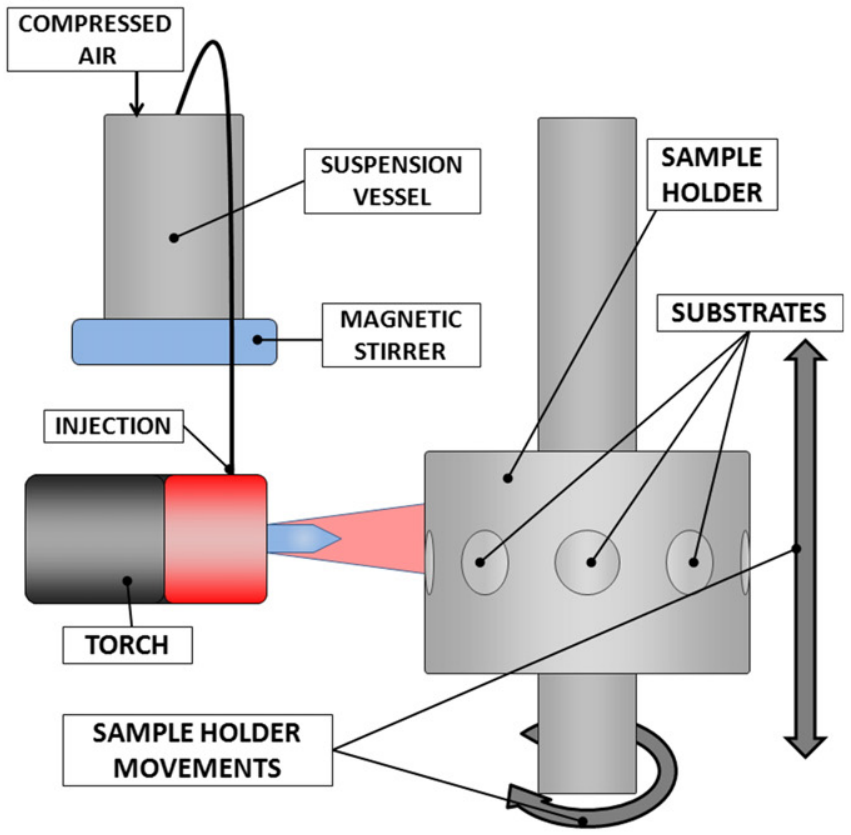

b
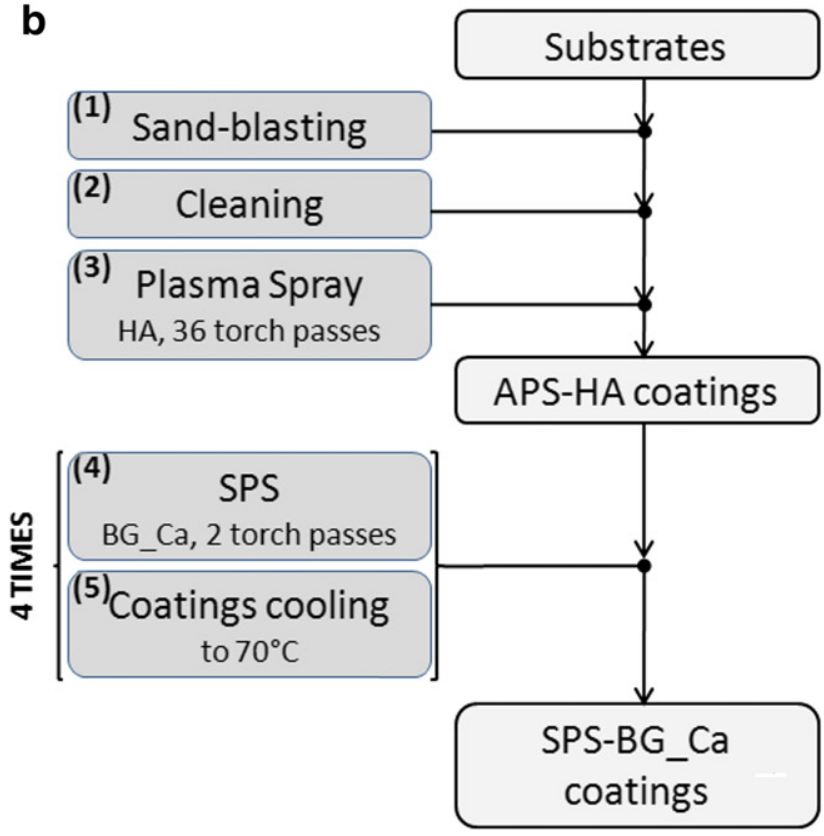

Fig. 1. Coatings' deposition process: (a) SPS set-up, (b) production scheme of the coatings.

remain amorphous and properly porous. The deposition parameters set for the two powders are specified in Table 1.

During the spraying sessions, the temperature of the coatings' surface was measured using an optical IN 5 Plus pyrometer (Impac).

\subsection{In vitro tests}

In order to investigate the effect of the glass topcoat on the reactivity in physiological fluids, both the APS-HA samples and the APS-HA/ SPS-BG_Ca samples were soaked in a simulated body fluid (SBF) according to the standard procedure proposed by Kokubo [27]. The SBF was refreshed every 2 days to mimic the dynamic conditions of the human body. The samples were removed from the SBF after time periods of 1 , 3,7 , and 14 days. The samples were washed with distilled water and left to dry at room temperature before further characterization. 
Table 1

Deposition parameters used to apply the pure HA coating by plasma spraying (APS-HA) and the bioactive glass topcoat by suspension plasma spraying (SPS-BG_Ca).

\begin{tabular}{lll}
\hline & APS-HA & SPS-BG_Ca \\
\hline Torch power [kW]: & 21 & 40 \\
Gases & & \\
Ar [slpm]: & 48 & 45 \\
$\mathrm{H}_{2}[$ slpm]: & 2 & 7.5 \\
Spray distance [mm]: & 100 & 70 \\
Torch speed [mm/s]: & 500 & 750 \\
Scan step [mm]: & 10 & 10 \\
Feedstock flow rate [g/min]: & 10 & 30 \\
Injector diameter [mm]: & 1 & 0.3 \\
Carrier gas flow rate [slpm]: & $\mathrm{Ar}, 3$ & - \\
Static pressure [MPa]: & - & 0.17 \\
Number of torch passes: & 36 & $2 \times 4$ runs \\
\hline
\end{tabular}

\subsection{Characterization}

The samples were analysed before and after soaking in SBF by different techniques.

The surface of the coatings was investigated by X-ray diffraction, XRD, with an X'pert PRO diffractometer (PANalytical, Almelo, The Netherlands) equipped with the X'Celerator detector, and employing $\mathrm{Cu}-\mathrm{K} \alpha$ radiation. Diffraction patterns were collected in the $10^{\circ}-70^{\circ} 2 \theta$ range (step size: $0.017^{\circ}$, step time: $71.12 \mathrm{~s}$ ).

An accurate microstructural analysis was carried out on the coatings' surfaces and polished cross sections by means of an environmental scanning electron microscope, ESEM (ESEM Quanta 200-FEI Company, Eindhoven, The Netherlands) coupled with an X-EDS microanalysis system (Inca, Oxford Instruments, U.K.). The microscope was operated both in high-vacuum and low-vacuum modes (pressure: $60 \mathrm{~Pa}$ ).

The coatings' surface was analysed by micro-Raman spectroscopy (Jobin-Yvon Raman Microscope Spectrometer, HORIBA Jobin Yvon S.A.S., Villeneuve d'Ascq, France). The laser source emits $20 \mathrm{~mW}$ at $632.8 \mathrm{~nm} ; 100 \times$ objective and no filters were employed.

\section{Results and discussion}

During the deposition of the APS-HA layer, the surface temperature did not exceed $250{ }^{\circ} \mathrm{C}$ and, at the end of the process, the temperature was about $200{ }^{\circ} \mathrm{C}$ (Fig. 2). During deposition of the SPS-BG_Ca topcoat, the temperature was slightly higher, with an average value of about $250{ }^{\circ} \mathrm{C}$ and local peaks of $330{ }^{\circ} \mathrm{C}$. However such values are relatively low with respect to those usually achieved in SPS deposition with ethanol [28]. In fact, the final parameters (listed in Table 1) were purposely defined to avoid an excessive heat flux to the coating in order to prevent the glass from crystallizing. This also limited the sintering process and therefore it resulted in a porous glass topcoat, which is expected to enhance its bioactivity [28]. To reduce the heat flux to the sample, the spraying distance was set to $70 \mathrm{~mm}$ and the glass topcoat was sprayed in four discontinued spray runs, with two torch passes for each run. Moreover, in order to control the surface temperature, the samples were cooled down to the temperature below $70{ }^{\circ} \mathrm{C}$ before starting each runs (Fig. 2b).

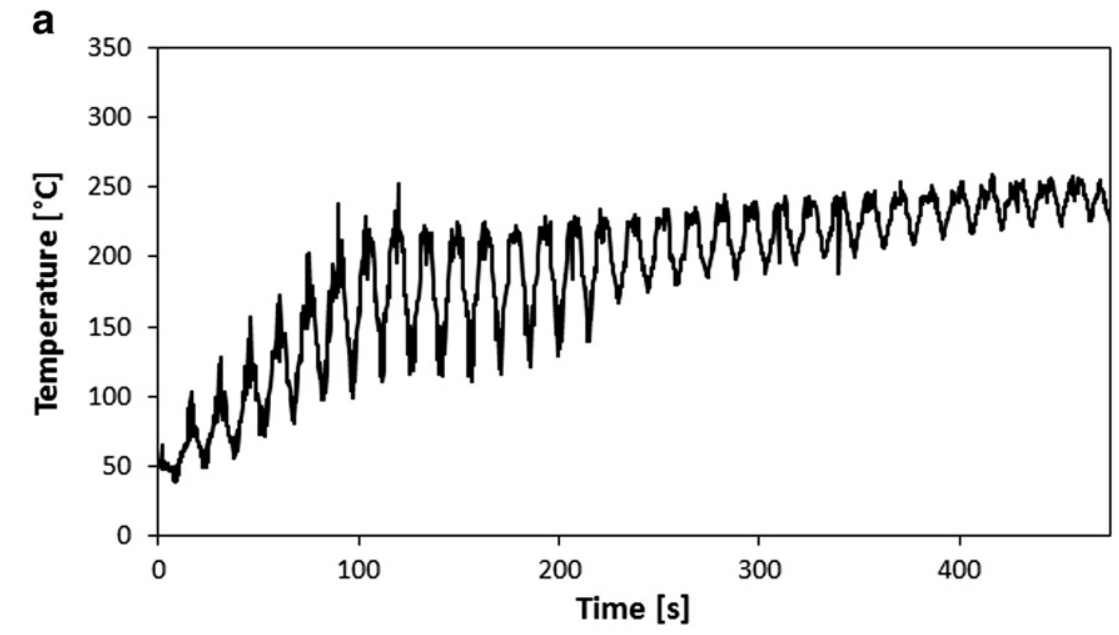

b
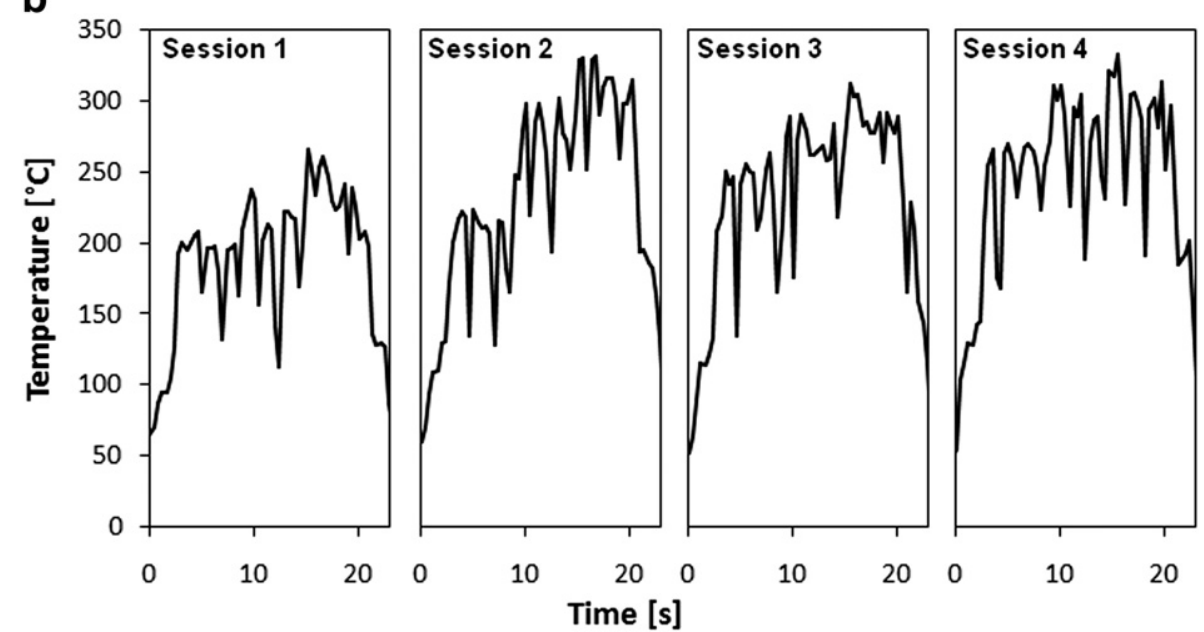

Fig. 2. Substrate temperature measured during spray sessions: (a) atmospheric plasma spray deposition of HA, (b) suspension plasma spray deposition of BG_Ca. 
As shown in Fig. 3, the XRD confirmed that the HA coating basically preserved its phase composition after the deposition. In fact, the spectrum of the APS-HA coating is similar to that of the original HA feedstock powder. However some secondary phases could be also detected, which resulted from a partial decomposition of the HA. In particular, the peaks in the $29^{\circ}-31^{\circ} 2 \theta$ range could be associated to the formation of tricalcium phosphate, TCP, and tetra-calcium phosphate, TTCP. The peak at $2 \theta=37.5^{\circ}$ corresponded to $\mathrm{CaO}$. Since the relative amounts of the decomposition phases in HA coatings may be linked to the relative intensity of the corresponding peaks in XRD patterns [32], it is likely that the thermal decomposition of the APS-HA coatings was very limited, since the peaks associated to the secondary phases were relatively weak. The limited decomposition of HA could have been favoured by the relatively low temperature of particles in-flight in the plasma jet, resulting from the low enthalpy of the plasma gas. Indeed, it is known from the literature that HA is prone to decompose [33], since it loses its $\mathrm{OH}^{-}$groups (de-hydroxylation) at high temperature, with a twostep process resulting first in the formation of oxyhydroxyapatite and then of oxyapatite [34]. If the temperature does not exceed a critical point, these new phases can return into HA phase in the presence of water [35]. Otherwise, if the critical temperature is surpassed, the HA crystal structure changes and suffers a complete and irreversible dehydroxylation [36]. If the temperature increases further, HA starts to decompose to other calcium phosphates, such as TCP and TTCP. These phases, in turn, can degrade into calcium oxide and phosphorus pentoxide $[34,36]$. Even if the thermal decomposition is affected by several circumstances, such as the environment [37] and the initial purity and degree of crystallinity of HA $[38,39]$, the critical point beyond which the decomposition is irreversible is about $1350{ }^{\circ} \mathrm{C}$ [36].

Fig. 3 also shows that, in the diffraction spectrum of the APS-HA/ SPS-BG_Ca sample, a broad band between $25^{\circ}$ and $35^{\circ}(2 \theta)$ was present, as often observed in silicate glasses. In addition, some new weak peaks could be detected, which may be associated with a calcium silicate, $\mathrm{Ca}_{2} \mathrm{SiO}_{4}$ (larnite). It is interesting to note that in the relatively $\mathrm{Na}_{2} \mathrm{O}$ poor BG_Ca glass a calcium silicate, instead of a sodium-calcium silicate developed, which is the typical outcome of the crystallization of 45S5 Bioglass ${ }^{\circledR}$ and other $\mathrm{Na}_{2} \mathrm{O}$-rich bioglasses [26]. Moreover, well-defined peaks could be attributed to the HA layer underneath the glass topcoat. The partial transparency of the topcoat to the X-rays resulted from the intrinsic properties of silicate glasses, as previously observed for other silicate-based bioactive glass coatings [40], and from the structure of

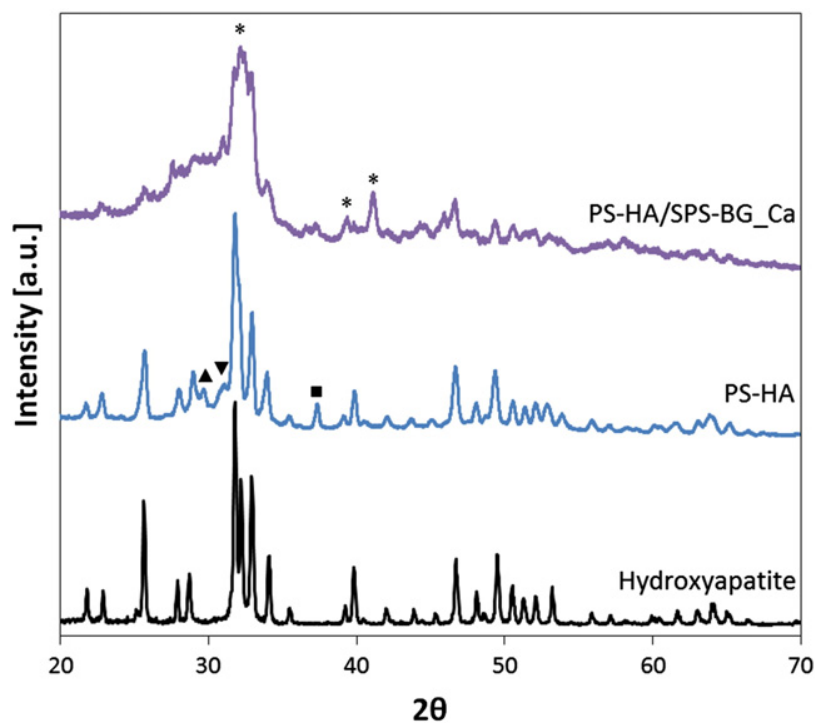

Fig. 3. Comparison between the X-ray diffraction pattern of the commercial HA feedstock powder and those of the coatings. Symbols: *, larnite $\left(\mathrm{Ca}_{2} \mathrm{SiO}_{4}, 01-070-0388\right) ; \mathbf{\Delta}$, TTCP (00-025-1137); $\mathbf{\nabla}, \mathrm{TCP}(00-009-0169) ; \mathbf{\square}, \mathrm{CaO}$ (01-075-0264); the peaks without symbol are due to HA (01-089-6437). the topcoat itself, which was highly porous and relatively thin, as confirmed by the ESEM inspection described below.

The microstructure of the APS-HA samples was compact, with relatively low porosity, as shown in Fig. 4a. Some dark areas could be observed in the cross section. Since the EDS analysis (Fig. 5) confirmed that they were composed of $\mathrm{HA}$, with atomic proportions analogous to those of the surrounding light-grey material, it is possible that such dark areas were the cross sections of unmelted HA particles incorporated into the coating. In fact, depending on the deposition conditions, partially molten or completely unmelted particles may remain in HA coatings produced by thermal spray techniques [41]. The surface of the APS-HA coatings (Fig. 4b) displayed both large splats, with diameters measuring some tens of microns, and areas with finer grains.

The inspection of the cross section of the APS-HA/SPS-BG_Ca samples confirmed that the glass topcoat was relatively thin, with typical thickness of about $20 \mu \mathrm{m}$ (Fig. 6a). Most of all, the glass layer was characterised by a very fine microstructure, which is a distinctive feature of SPS coatings [23]. Moreover the BG_Ca topcoat was more porous than the atmospheric plasma sprayed HA layer. The rich porosity that characterises the glass topcoat is expected to enhance the implant osteointegration in vivo, since it confers a "trabecular-like" structure to the coating [42]. With regard to the surface morphology, the glass topcoat was extremely rough, as shown in Fig. 6b. A high roughness may be extremely advantageous, since it increases the specific surface area available for chemical reactions and hence favours the cell attachment [43]. Moreover, the surface roughness and morphology have significant impact on protein adsorption [44]. To conclude, very fine needle-like structures could be observed on the surface of the APSHA/SPS-BG_Ca coatings. It is possible that the structure results from the crystals of the $\mathrm{Ca}_{2} \mathrm{SiO}_{4}$ phase identified by the XRD.

After the immersion in SBF, the surface of both types of coatings (with and without the glass topcoat) was covered by dome-like structures which are typical of hydroxy-carbonate-apatite (HCA) deposits
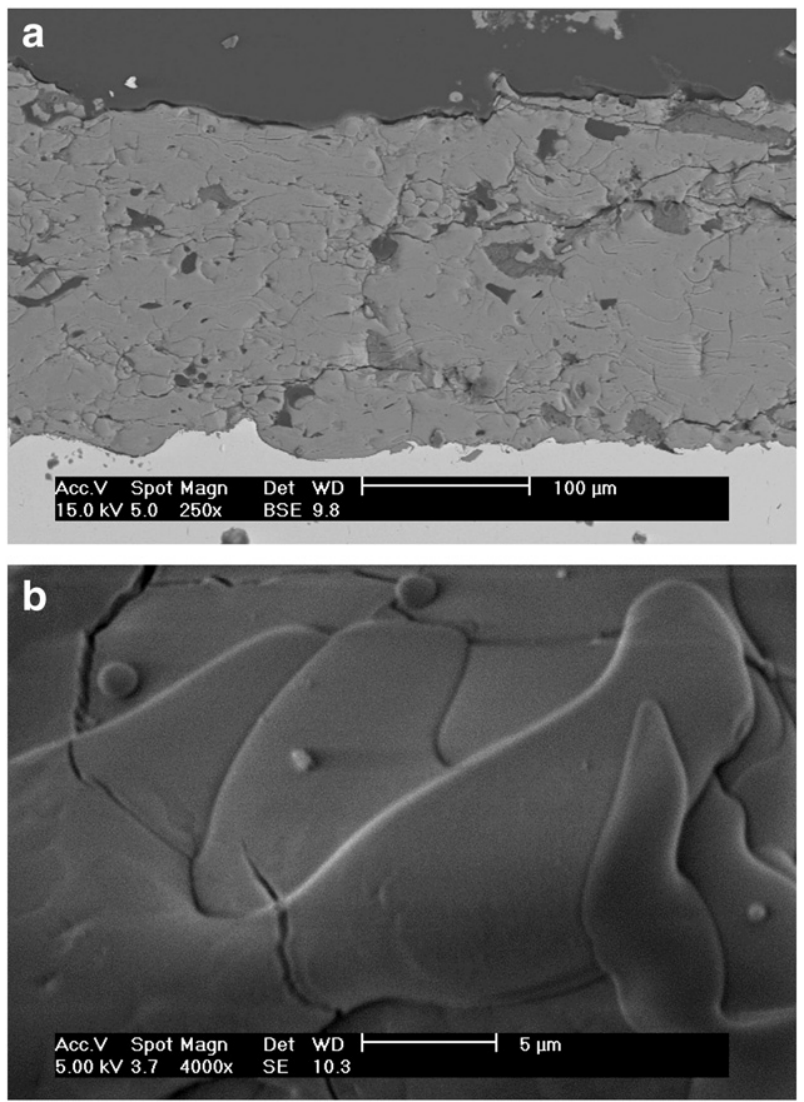

Fig. 4. APS-HA coatings: (a) cross section, (b) surface. 

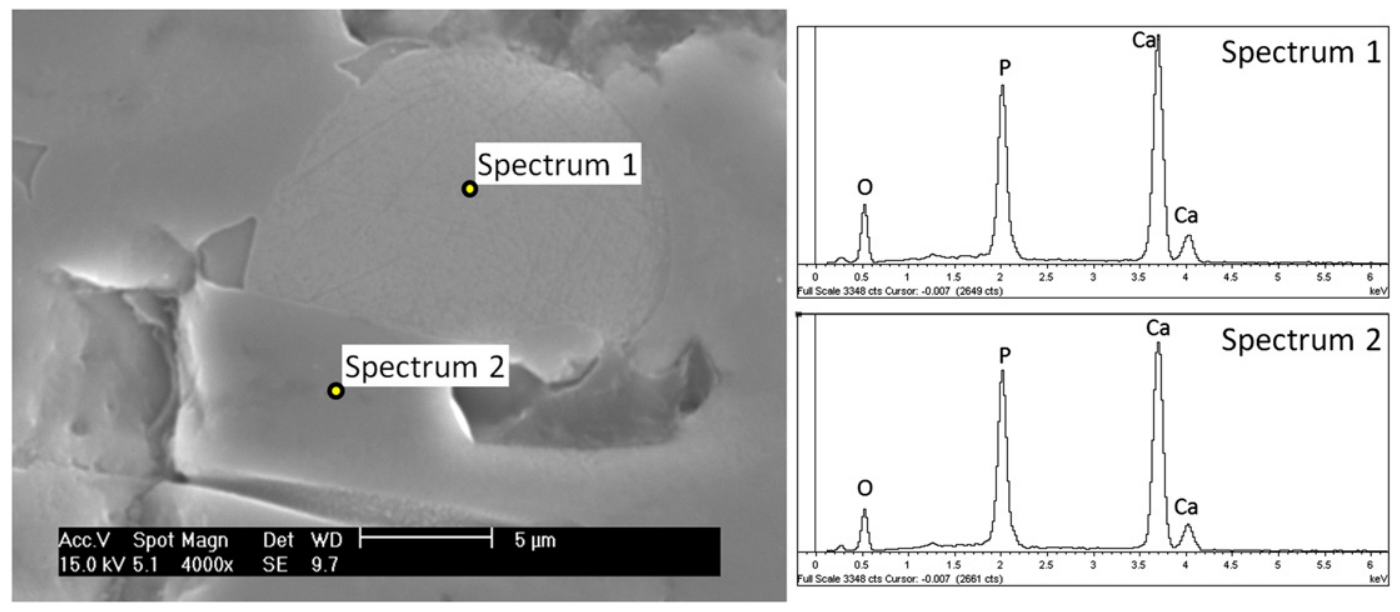

Fig. 5. Details of the APS-HA cross section and corresponding EDS microanalyses.

grown in vitro $[45,46]$. However, a direct comparison between the two types of samples (Fig. 7) suggests that the APS-HA/SPS-BG_Ca system reacted more rapidly than the APS-HA one. Indeed, the surface of the glass topcoat quickly assumed a more globular morphology. Moreover it is interesting to note that the fine crystalline structures originally present on the APS-HA/SPS-BG_Ca sample completely disappeared already after 1 day in SBF.

Fig. 8 propose some representative images of the cross section of the samples soaked in SBF. After one day, a few micron-thick reaction layer grew on the APS-HA coating (Fig. 8a); as shown by the X-EDS analysis (Table 2 ), such layer had a $\mathrm{Ca} / \mathrm{P}$ ratio of 1.49 , a value observed already in calcium-deficient amorphous calcium phosphate (ACP) [47].

Instead, if the APS-HA/SPS-BG_Ca system is considered (Fig. 8b), after one day in SBF the glass topcoat underwent a through-thickness
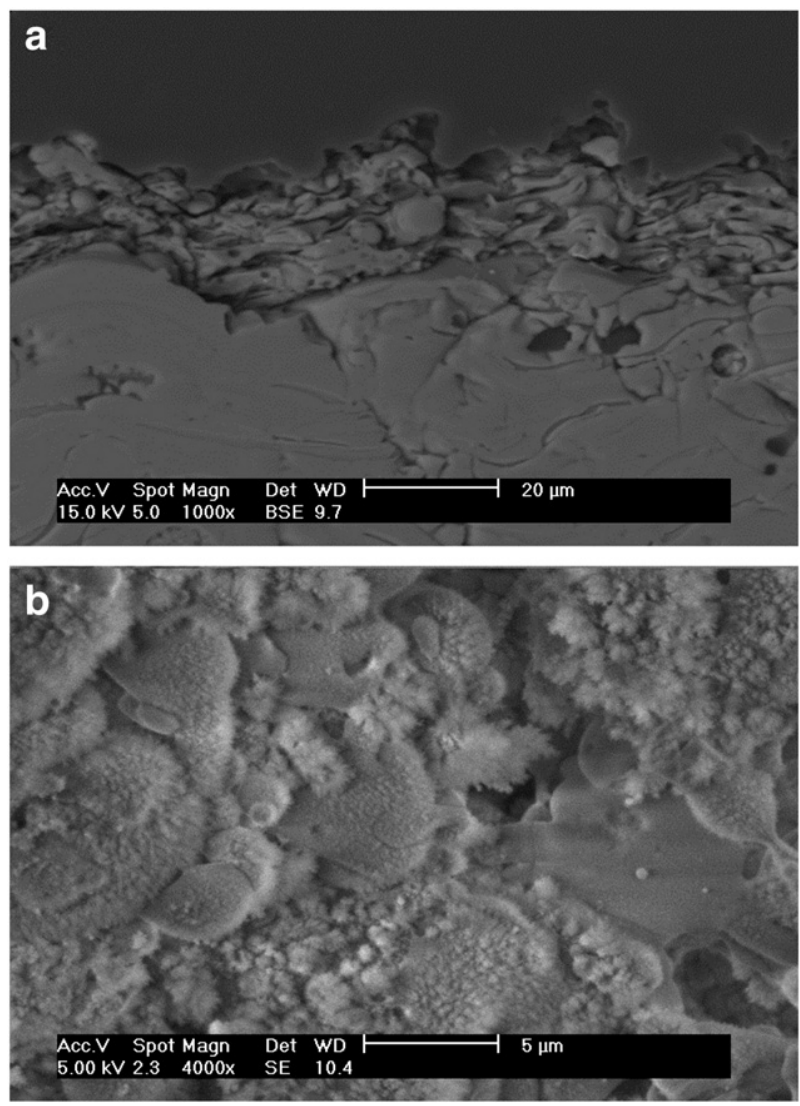

Fig. 6. APS-HA/SPS-BG_Ca coatings:(a) cross section; (b) surface. reaction and only silicon and oxygen could be detected by the X-EDS analysis (Table 2), thus suggesting a silica gel layer developed on the surface. The very high reactivity of the topcoat was due to the concomitant effect of the intrinsic bioactivity of the BG_Ca glass [26] and of the porous microstructure of the layer. In fact the rich porosity of the topcoat favoured the penetration of SBF in depth and greatly increased the specific surface area available for the chemical reactions. Moreover it was observed that, already after one day in SBF, the silica gel layer, in turn, was covered by a very thin deposit of calcium phosphate. The progressive conversion of the original glass to silica gel and the subsequent growth of the hydroxy-carbonate apatite (HCA) surface layer detected on the APS-HA/SPS-BG_Ca system are similar to the mineralization reactions occurring on conventional bioactive glasses in bulk form [48]. The growth of the calcium phosphate layer on the APS-HA/SPS-BG_Ca sample continued for increasing immersion time and, after one week in SBF, the original glass topcoat has disappeared, since it was completely converted to HCA (Fig. 8c) with a $\mathrm{Ca} / \mathrm{P}$ ratio close to that of stoichiometric HA, i.e. $\mathrm{Ca} / \mathrm{P} \sim 1.67$ [3] (Table 2). It is interesting to note that the HCA precipitates were perfectly integrated into the coating, since the interface was not easily detectable.

As a general consideration, according to the SEM outcomes, the reaction kinetics proceeded faster on the APS-HA/SPS-BG_Ca system than on the pure APS-HA coating. In fact, the HCA layer grown on the APSHA sample after 14 days in SBF was thinner than that grown on the APS-HA/SPS-BG_Ca system after 7 days in SBF, as apparent from the comparison of the corresponding SEM images in Fig. 8d and c.

The XRD pattern of the APS-HA sample reported in Fig. 9 (bold traces) did not show sensible variations as a result of the immersion in SBF. However, starting from the first day of immersion, the peaks associated to the secondary phases (TCP, TTCP and $\mathrm{CaO}$ ) gradually disappeared. More precisely, the peak associated to $\mathrm{CaO}$ vanished already after one day of immersion, whereas the peaks of TTCP and TCP were not visible after seven days. On the other hand, the peaks of HA did not vary with increasing immersion time.

In contrast to this, the XRD patterns of the APS-HA/SPS-BG_Ca samples (Fig. 9, thin traces) strongly changed after immersion in SBF. Starting from the first day, the main peaks of HCA could be identified, although they were very broad. The large width of the peaks was indicative of the poor crystallinity of HCA, an effect that is often observed for in vitro grown HCA [49]. At the same time, the peaks due to $\mathrm{Ca}_{2} \mathrm{SiO}_{4}$ disappeared, supporting the hypothesis that such crystallizations were mainly constituted by superficial fine crystals, readily dissolved by the SBF. The peak at $2 \theta=29.4^{\circ}$, observed occasionally in the XRD spectra of the soaked samples, is due to $\mathrm{CaCO}_{3}$, a mineral that may co-precipitate in vitro with HCA $[27,50]$. 

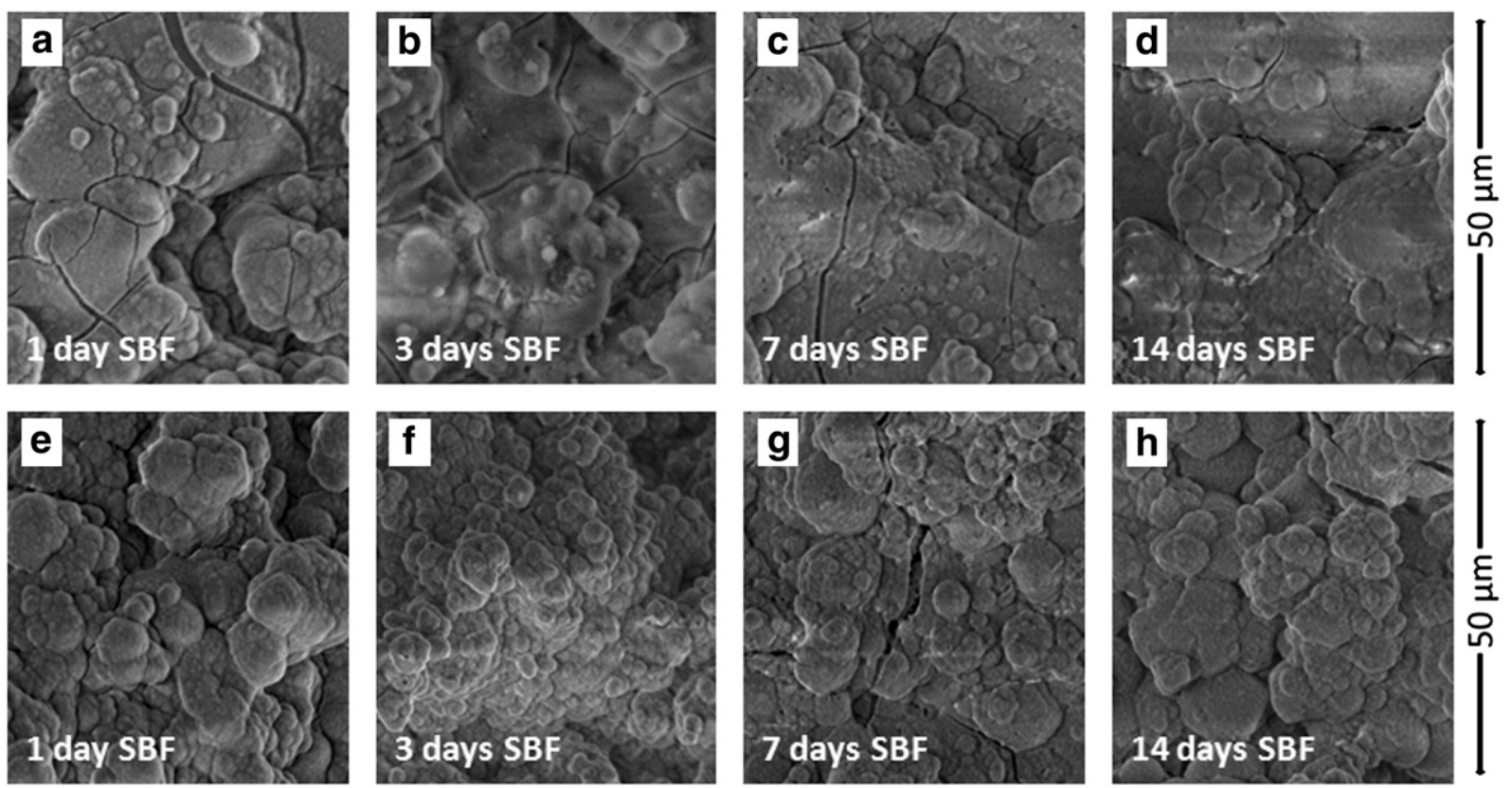

Fig. 7. Surface morphology after in vitro tests: APS-HA samples (a, b, c, d); APS-HA/SPS-BG_Ca samples (d, e, f, g). The scale bar is the same for all images, secondary electrons.

Further information on the reactions occurring in SBF was obtained by means of Raman micro-spectroscopy. Fig. 10 compares the spectra of the APS-HA samples (bold traces) and those of the APS-HA/ SPS-BG_Ca ones (thin traces). In particular, if the pattern of the as-sprayed APS-HA coating is considered, the peak associated to the symmetrical stretching of the $\mathrm{PO}_{4}$ group, at about $960 \mathrm{~cm}^{-1}$, can be separated in two different contributions, namely a broad and weak peak, and a sharp and intense one. The latter can be associated to HA, while the former is thought to be due to the decomposition phases: ACP, TTCP and TCP [51]. After immersion in SBF (Fig. 10, bold traces), the Raman peaks associated with HA became broader and less defined, but they did not shift to different wavenumbers. The gradual change in the peak shape was likely due to the precipitation of poorly crystallized HCA on the original surface.

The Raman spectra acquired on the surface of the APS-HA/ SPS-BG_Ca coatings showed a marked change after the immersion in SBF (Fig. 10, thin traces). In the spectrum of the as-sprayed coating, three bands related to the BG_Ca glass were observed: a first band at
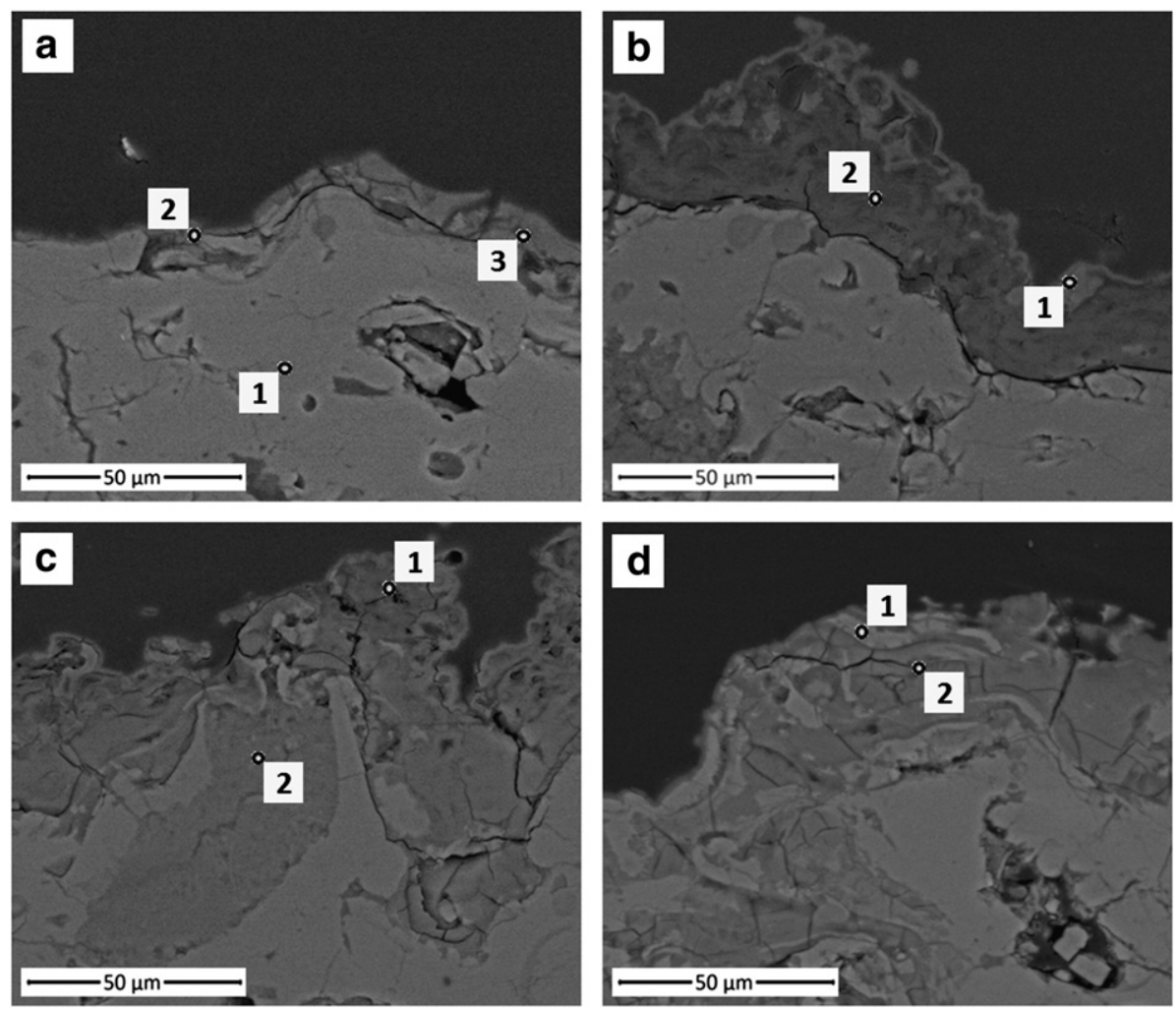

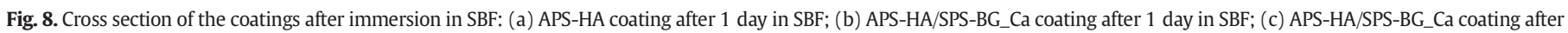
7 days in SBF; (d) APS-HA coating after 14 days in SBF. 
Table 2

Coatings' composition evaluated by X-EDS analysis performed on the cross-section of SBF soaked samples (Fig. 8).

\begin{tabular}{lllllll}
\hline & Point & Ca & P & Si & O & Ca/P \\
\hline APS-HA, 1 day in SBF (Fig. 8a) & 1 & 24.38 & 15.05 & - & 60.57 & 1.62 \\
& 2 & 22.95 & 15.46 & - & 61.59 & 1.49 \\
& 3 & 22.58 & 15.86 & - & 61.56 & 1.49 \\
APS-HA/SPS-BG, 1 day in SBF (Fig. 8b) & 1 & 49.53 & 0.27 & - & 50.20 & - \\
& 2 & - & - & 33.33 & 66.67 & - \\
APS-HA/SPS-BG, 7 days in SBF (Fig. 8c) & 1 & 24.48 & 14.53 & - & 60.89 & 1.68 \\
& 2 & 23.15 & 15.37 & - & 61.48 & 1.51 \\
APS-HA, 14 days in SBF (Fig. 8d) & 1 & 23.04 & 15.41 & - & 61.56 & 1.50 \\
& 2 & 22.36 & 15.80 & - & 61.85 & 1.42 \\
\hline
\end{tabular}

about $635 \mathrm{~cm}^{-1}$ and a second one in the range from 800 to $1150 \mathrm{~cm}^{-1}$, which are both associated to the $\mathrm{Si}-\mathrm{O}-\mathrm{Si}$ bonds in silica, and a third band at $950 \mathrm{~cm}^{-1}$, which is due to the symmetrical stretching of the $\mathrm{PO}_{4}$ group [52]. Then, after soaking in SBF, the new peaks of the precipitated HCA progressively replaced the signals of the original glass and they steadily became sharper with increasing immersion time. From this point of view, the evolution of the Raman spectra of the APS-HA/ SPS-BG_Ca samples in SBF corresponded to that of the XRD patterns, since in both cases the growth of HCA could be clearly detected.

Moreover, with regard to the Raman spectra, it is worth noting that, after immersion in SBF, a new peak appeared at approximately $1070 \mathrm{~cm}^{-1}$, which is assigned to the carbonate group, thus confirming that the precipitated HA was indeed carbonated [52]. The comparison between the spectra of the APS-HA coatings and the APS-HA/

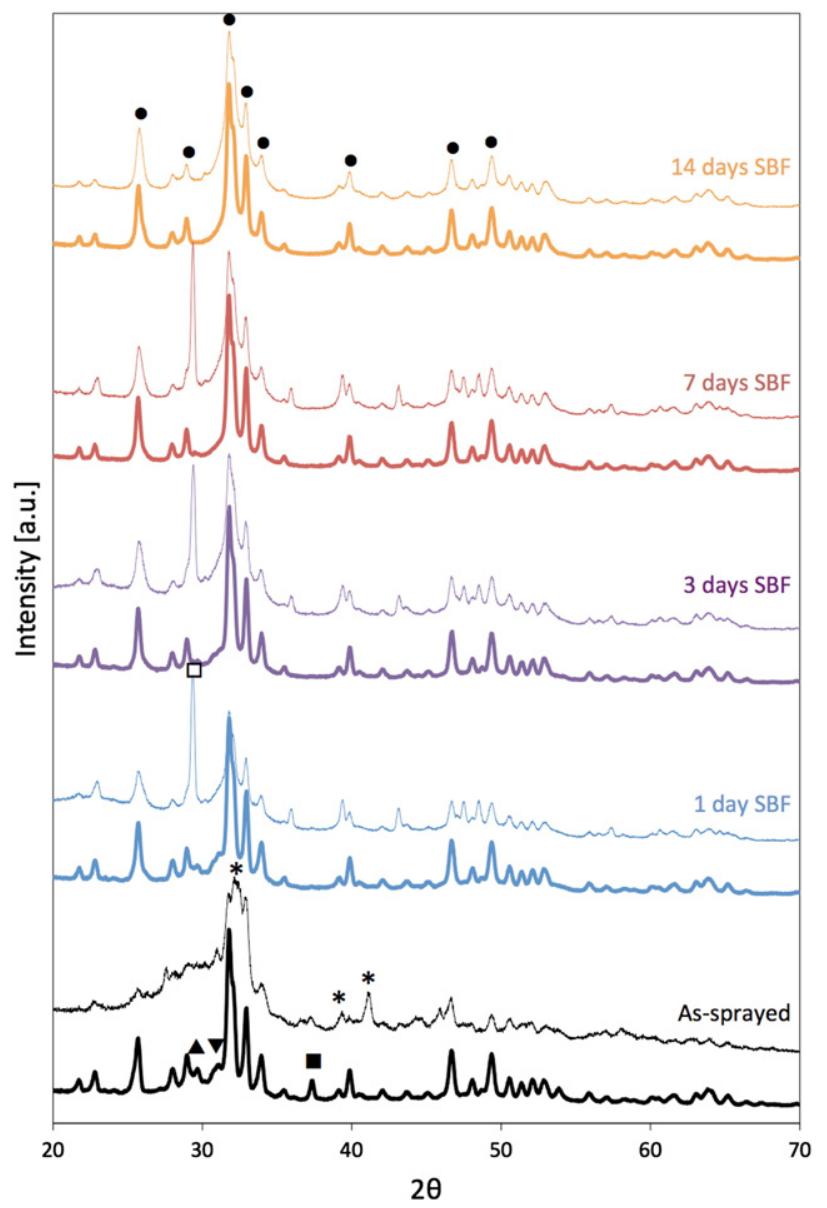

Fig. 9. Evolution of the XRD spectra of the APS-HA samples (bold trace) and of those of the APS-HA/SPS-BG_Ca samples (thin trace) after in vitro tests. The spectra of the as-sprayed samples are included as a term of comparison. Symbols: *, larnite $\left(\mathrm{Ca}_{2} \mathrm{SiO}_{4}\right) ; \mathbf{\Delta}, \mathrm{TTCP} ; \mathbf{\nabla}$, TCP; $\mathbf{\square}, \mathrm{CaO} ; \square, \mathrm{CaCO}_{3} ; \bullet$, $\mathrm{HCA}$. The peaks without symbol are due to HA.

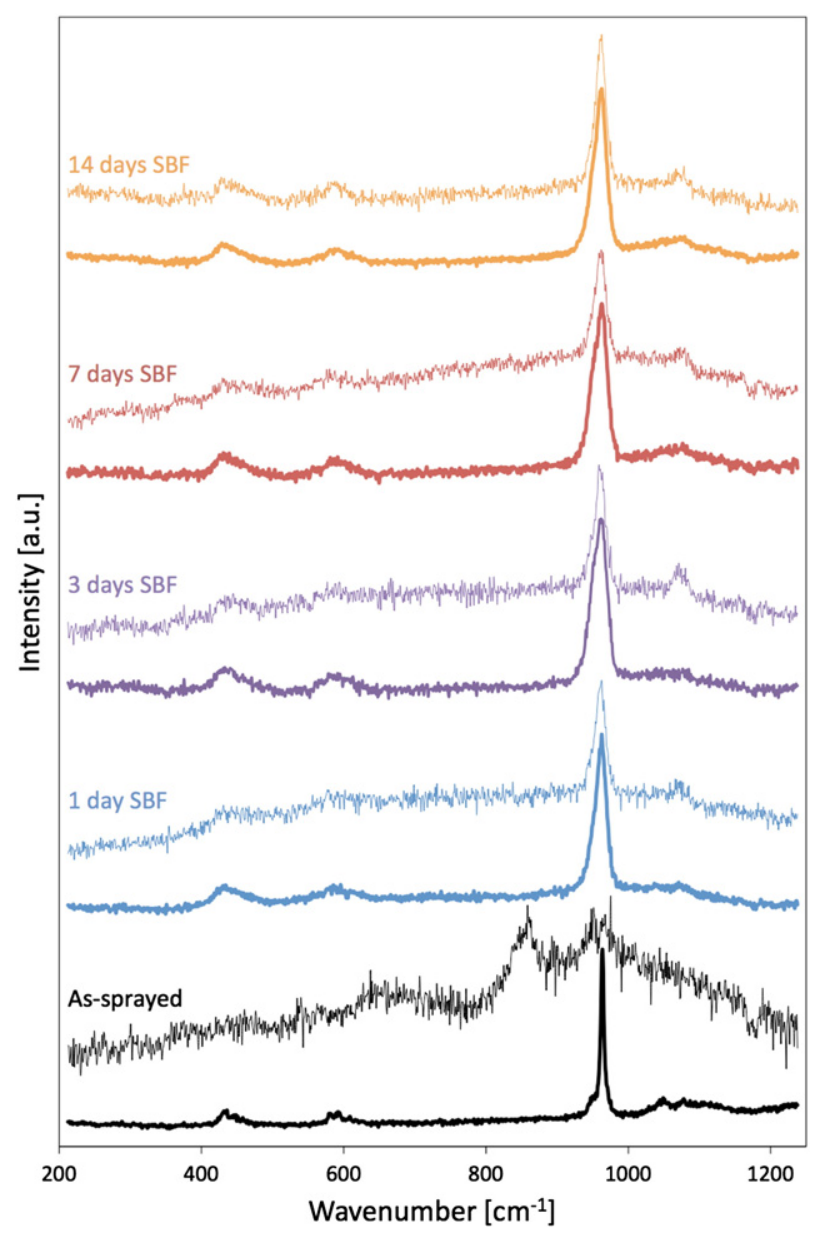

Fig. 10. Evolution of the Raman spectra of the APS-HA samples (bold trace) and of those of the APS-HA/SPS-BG_Ca samples (thin trace) after in vitro tests. The spectra of the assprayed samples are included as a term of comparison.

SPS-BG_Ca (Fig. 10) shows that the peak at $1070 \mathrm{~cm}^{-1}$ is stronger for the latter. Since the peak is strictly connected to the carbonate group of the HCA grown in SBF, this discrepancy between the Raman spectra further confirms that the APS-HA/SPS-BG_Ca samples reacted in SBF more quickly than the APS-HA ones.

Currently the discussion is still open on the real significance of in vitro tests. Indeed, the SBF (like other media, such as Hanks' balanced salt solution HBSS, Na-lactate and lactic acid-buffered physiological solution [53]) is simple salt solutions and, since it does not contain cells, it is not able to reproduce the real complexity of a biological environment [54]. However it is generally recognized that SBF tests may be useful to evaluate the ability to promote the growth of a HCA surface layer, which is similar to the mineral component of human bone [27]. So, even if the apatite forming ability does not automatically imply the bone-bonding ability [55], the development of a HCA layer in SBF may be still considered a favourable indicator of the tendency to support the mineralization process [27]. The results of the SBF tests therefore suggest that the addition of a bioactive glass topcoat may be effective to improve the mineralizing ability of a standard plasma sprayed HA coating, especially if the glass topcoat possesses a fine microstructure, with a controlled porosity.

\section{Conclusions}

In this study standard HA coatings with and without a functional bioactive topcoat were produced and tested. In particular, the HA coatings were sprayed through atmospheric plasma spray on stainless steel substrates, while the glass topcoat was produced via suspension plasma spray. 
The bioactive glass topcoat showed high porosity and rough surface, which constitute an optimum microstructure to promote bioactivity. The coatings, with and without the glass topcoat, were tested in vitro by immersion in a simulated body fluid (SBF). It is interesting to observe that the samples with the glass topcoat showed a greater reactivity with respect to pure HA coatings. In fact, both types of coatings were covered by a calcium-phosphate layer after soaking in SBF, however the bioactive glass topcoat was completely converted into hydroxy-carbonateapatite in less than one week. This phenomenon was confirmed by both ESEM investigation (with X-EDS microanalysis), and by X-ray diffraction. Furthermore, the Raman analysis suggested that the HCA developed on the bioactive glass topcoat exhibited a greater carbonation level with respect to the layer that developed on pure HA.

Nevertheless, this is only a preliminary trial, since cell tests are necessary to determine the biological effectiveness of the topcoat. In this way it could be possible to verify whether the high porosity of the topcoat, associated to the intrinsic bioactivity of the glass, could be able to increase the absorption of metabolites and the cellular activity.

\section{Acknowledgements}

The Vinci Program (Italian-French University) support for Dr. A. Cattini is gratefully acknowledged.

\section{References}

[1] http://www.boneandjointburden.org/consulted(on March 18, 2013).

[2] A. Kolk, J. Handschel, W. Drescher, D. Rothamel, F. Kloss, M. Blessmann, M. Heiland, K.-D. Wolff, R. Smeets, J. Cranio Maxillofac. Surg. 40 (2012) 706.

[3] S.V. Dorozhkin, Materials 2 (2009) 399.

[4] S. Bose, S. Tarafder, Acta Biomater. 8 (2012) 1401

[5] H. Liang, B. Shi, A. Fairchild, T. Cale, Vacuum 73 (2004) 317.

[6] H. Cao, X. Liu, Int. J. Appl. Ceram. Technol. 10 (2013) 1.

[7] K. de Groot, J.G.C. Wolke, J.A. Jansen, Proc. Inst. Mech. Eng. H 212 (1998) 137.

[8] W.N. Capello, J.A. D'Antonio, W.L. Jaffe, R.G. Geesink, M.T. Manley, J.R. Feinberg, Clin. Orthop. Relat. Res. 453 (2006) 75.

[9] P. Ducheyne, S. Radin, L. King, J. Biomed. Mater. Res. 27 (1993) 25.

[10] Y. Cai, S. Zhang, X. Zeng, Y. Wang, M. Qian, W. Weng, Thin Solid Films 517 (2009) 5347.

[11] K. McLeod, S. Kumar, R.St.C. Smart, N. Dutta, N.H. Voelcker, G.I. Anderson, R. Sekel, Appl. Surf. Sci. 253 (2006) 2644

[12] B.-D. Hahn, J.-M. Lee, D.-S. Park, J.-J. Choi, J. Ryu, W.-H. Yoon, J.-H. Choi, B.-K. Lee J.-W. Kim, H.-E. Kim, S.-G. Kim, Thin Solid Films 519 (2011) 8085.

[13] A. Sola, D. Bellucci, V. Cannillo, A. Cattini, Surf. Eng. 27 (2011) 560.

[14] X. Liu, M. Morra, A. Carpi, B. Li, Biomed. Pharmacother. 62 (2008) 526.

[15] M. Roy, B.V. Krishna, A. Bandyopadhyay, S. Bose, Acta Biomater. 4 (2008) 324

[16] S. Kozerski, L. Pawłowski, R. Jaworski, F. Roudet, F. Petit, Surf. Coat. Technol. 204 (2010) 1380.
[17] J.R. Jones, Acta Biomater. 9 (2013) 4457.

[18] L.L. Hench, J. Mater. Sci. Mater. Med. 17 (2006) 967.

[19] M.N. Rahaman, D.E. Day, B. Sonny Bal, Q. Fu, S.B. Jung, L.F. Bonewald, A.P. Tomsia, Acta Biomater. 7 (2011) 2355.

[20] A.R. Boccaccini, Q.Z. Chen, L. Lefebvre, L. Gremillard, J. Chevalier, Faraday Discuss. 136 (2007) 27.

[21] D. Bellucci, V. Cannillo, A. Sola, Sci. Sinter. 42 (2010) 307.

[22] D. Bellucci, A. Sola, V. Cannillo, J. Am. Ceram. Soc. 95 (2012) 1313.

[23] L. Pawłowski, Surf. Coat. Technol. 203 (2009) 2807.

[24] H. Kassner, R. Siegert, D. Hathiramani, R. Vassen, D. Stöver, J. Therm. Spray Technol. 17 (2008) 115.

[25] M.G.W. Lockyer, D. Holland, R. Dupree, J. Non-Cryst. Solids 188 (1995) 207.

[26] A. Sola, D. Bellucci, M.G. Raucci, S. Zeppetelli, L. Ambrosio, V. Cannillo, J. Biomed. Mater. Res. A 100A (2012) 305.

[27] T. Kokubo, H. Takadama, Biomaterials 27 (2006) 2907.

[28] S. Dyshlovenko, B. Pateyron, L. Pawłowski, D. Murano, Surf. Coat. Technol. 179 (2004) 110

[29] A. Cattini, L. Łatka, D. Bellucci, G. Bolelli, A. Sola, L. Lusvarghi, L. Pawłowski, V. Cannillo, Surf. Coat. Technol. 220 (2013) 52.

[30] R.M. Pilliar, in: R. Narayan (Ed.), Biomedical Materials, Springer Science + Business Media, LLC, New York, NY, USA, 2009, pp. 40-81, (esp. 55).

[31] S. Dyshlovenko, L. Pawłowski, P. Roussel, D. Murano, A. Le Maguer, Surf. Coat. Technol. 200 (2006) 3845

[32] Z. Mohammadi, A.A. Ziaei-Moayyed, A. Sheikh-Mehdi Mesgar, Appl. Surf. Sci. 253 (2007) 4960.

[33] P. Cheang, K.A. Khor, Biomaterials 17 (1996) 537.

[34] R.B. Heimann, Surf. Coat. Technol. 201 (2006) 2012.

[35] X. Zhang, X. Li, H. Fan, X. Liu, Key Eng. Mater. 330-332 (2007) 107.

[36] A.J. Ruys, M. Wei, C.C. Sorrell, M.R. Dickson, A. Brandwood, B.K. Milthorpe, Biomaterials 16 (1995) 409.

[37] K.A. Gross, C.C. Berndt, J. Biomed. Mater. Res. 15 (1998) 580.

[38] S. Raynaud, E. Champion, D. Bernache-Assollant, P. Thomas, Biomaterials 23 (2002) 1065.

[39] Y. Chen, X. Miao, Biomaterials 26 (2005) 1205.

[40] L. Altomare, D. Bellucci, G. Bolelli, B. Bonferroni, V. Cannillo, L. De Nardo, R. Gadow, A. Killinger, L. Lusvarghi, A. Sola, N. Stiegler, J. Mater. Sci. Mater. Med. 22 (2011) 1303.

[41] K.A. Khor, H. Li, P. Cheang, Biomaterials 25 (2004) 1177.

[42] C. Vitale-Brovarone, F. Baino, F. Tallia, C. Gervasio, E. Verné, J. Mater. Sci. Mater. Med. 23 (2012) 2369

[43] D.D. Deligianni, N.D. Katsala, P.G. Koutsoukos, Y.F. Missirlis, Biomaterials 22 (2001) 87.

[44] K. Rechendorff, M.B. Hovgaard, M. Foss, V.P. Zhdanov, F. Besenbacher, Langmuir 22 (2006) 10885.

[45] J. Li, H. Liao, M. Sjöström, Biomaterials 18 (1997) 743

[46] D.K. Pattanayak, Mater. Sci. Eng. C 29 (2009) 1709.

[47] H.M. Kim, T. Himeno, T. Kokubo, T. Nakamura, Biomaterials 26 (2005) 4366.

[48] L.L. Hench, J. Am. Ceram. Soc. 81 (1998) 1705.

[49] C. Vitale Brovarone, E. Verné, P. Appendino, J. Mater. Sci. Mater. Med. 17 (2006) 1069.

[50] V. Cannillo, A. Sola, Ceram. Int. 35 (2009) 3389

[51] H. Li, B.S. Ng, K.A. Khor, P. Cheang, T.W. Clyne, Acta Mater. 52 (2004) 445.

[52] D. Bellucci, G. Bolelli, V. Cannillo, A. Cattini, A. Sola, Mater. Charact. 62 (2011) 1021.

[53] A. Pasinli, M. Yuksel, E. Celik, S. Sener, A.C. Tas, Acta Biomater. 6 (2010) 2282.

[54] M. Bohner, J. Lemaitre, Biomaterials 30 (2009) 2175.

[55] H. Pan, X. Zhao, B.W. Darvell, W.W. Lu, Acta Biomater. 6 (2010) 4181. 